\title{
The Role of Emotions and Social Information Processing in the Decision Processes of Aggressive Behavior
}

\author{
Takeyasu Kawabata ${ }^{1}$, Ken-ichi Ohbuchi ${ }^{2}$ \\ ${ }^{1}$ Department of Psychology, Shokei Gakuin University, Natori, Miyagi \\ ${ }^{2}$ Open University of Japan, Natori, Miyagi
}

Email address:

kawabata@shokei.ac.jp (T. Kawabata)

\section{To cite this article:}

Takeyasu Kawabata, Ken-ichi Ohbuchi. The Role of Emotions and Social Information Processing in the Decision Processes of Aggressive Behavior. Psychology and Behavioral Sciences. Vol. 8, No. 4, 2019, pp. 91-99. doi: 10.11648/j.pbs.20190804.12

Received: July 14, 2019; Accepted: August 12, 2019; Published: August 23, 2019

\begin{abstract}
The social information processing (SIP) model is an important element in theoretical accounts of aggressive behavior. Recently, several authors have suggested the integrations of emotions in the SIP model. The purpose of this study was to examine the validity of the revised SIP model of aggression with Japanese young people. In Study 1, 130 male Japanese students were given three scenarios depicting social conflicts and asked to rate the variables comprising the model. Structural equation analysis showed that hostile intent, anger and positive evaluation of aggressive behavior increased aggressive behavior, on the other hand, adaptive emotion regulation strategies decreased aggressive behavior. Hierarchical regression analysis revealed that the revised model was significantly better in the prediction of aggression than the original model. In study 2, 82 male Japanese delinquents were given the same materials as study1. The results substantially replicated the results of Study 1 , although emotion regulation did not work in this sample. There appear to be two possible interpretations. One possibility is that juvenile delinquents may be likely to engage in aggression because they tend to feel strong anger, and the uncontrolled anger distorts social perception to produce aggressive motivations. The other interpretation is that the research procedures adopted by the study 2 influenced the results. Both studies further indicated that the levels of variables of the revised model were significantly different between high aggressive and low aggressive participants.
\end{abstract}

Keywords: Aggression, Social Information Processing, Anger, Emotion Regulation

\section{Introduction}

\subsection{Social Information Processing Model and Aggression}

Social information processing has been given an important role in theoretical accounts of development and decisions to engage in aggressive behavior. Aggression is defined as a behavior that is intended to hurt or harm others [1]. A social information processing model $[2,3]$ was proposed to explain the social cognitive processes of children showing poor social competence that was an integration of Flavell's step theory of social inferences [4], Goldfried and d'Zurilla's problem-solving strategy training [5], Simon's [6] and Hayes' information-processing theories of cognitive problem solving [7], and McFall's [8,9] reformation of social skills theory. This model posited a sequence of cognitive steps that lead to behavioral responses, including aggression toward others [10]. The first step is the attention to and detection of the cues from the large stimulus array. The second step is the mental representation of those cues, involving an interpretation of the other person's intention. Third, this representation activates a specific interaction goal. Fourth, this goal selection generates one or more possible responses. Fifth, these responses are evaluated against the goal, and an optimal response is selected. Finally, the selected response is enacted.

In an experimental study in which children were observed entering a play group, and reacting to ambiguous provocation from other children, Dodge demonstrated that these social information processing variables predicted the level of social competence [2].

\subsection{SIP Model and Emotion Processes}

The SIP model consists of cognitive variables. Dodge regarded emotion as the energy that drives the entire process [2], and he did not explicitly include emotion as an essential component in the original SIP model $[3,11]$. Because it has 
been repeatedly reported that negative emotions instigate and enhance aggressive behavior, some studies assume that emotion is a crucial internal factor of aggressive behavior [12, 13]. For example, it has been demonstrated that short-tempered persons tend to behave aggressively [14] and that anger instigates homicide [15], child abuse [16], and domestic violence [17]. Considering the evidence, some researchers have attempted to revise the SIP model to include affective variables $[11,18,19]$.

De Castro confirmed Lemerise and Arsenio's model in which unregulated anger enhances aggressive behavior in social conflict situations and emotion regulation reduces it. $\mathrm{He}$ proposed a revised SIP model by adding affective variables to it, that is, anger and adaptive emotion regulation [20]. Emotion regulation is to control, modify, and manage emotional experiences and the expression of emotions [21]. In addition, de Castro, Merk, and Koops hypothesized that anger distorts cognitive process but emotion regulation suppresses the cognitive distortions and consequently reduces aggressive behavior [22]. Those authors demonstrated that, consistent with the hypothesis, non-aggressive children tended to show fewer cognitive biases to perceive the other party's hostile intention, to evaluate aggressive behavior less positively, to show less anger, and to have stronger emotion regulation than aggressive children in ambiguous provocative situations.

\subsection{The Cultural Aspects of Aggression and Emotion Processes}

It is known that culture has influence on anger. Cross-cultural research has repeatedly demonstrated that Japanese are less likely to overtly express anger than westerners [23]. However, it is suggested that such a cultural difference in anger is caused not only by suppression based on divergent display codes but also by internal emotion regulation. In a cross-cultural study of emotional processes among adolescents from five countries including Japan, Kornadt, Hayashi, Tachibana, Trommsdorff, and Yamauchi showed that although Japanese were sensitive to interpersonal frustrations, such as unfriendly or impolite behaviors, they were less likely to interpret opponent's intentions as malevolent, thereby reacting with less anger, than westerners and that when they really angered, they were not often engaged in overt aggression because they were more concerned with maintaining social relations than pursuing aggressive goals to defend or restore self-esteem or pride [24]. This indicates that Japanese, as cultural collectivists, are strongly oriented toward emotion regulation of anger and avoidance of aggressive confrontation because of interest in social maintenance.

These cross-cultural findings on anger suggest that when de Castro et al.'s model [22] be applied to Japanese, the role of emotion regulation may be more important in the determination of anger and aggression among Japanese than westerners. The revised SIP model was constructed based on the research evidence that was obtained from the Western samples; the model had not yet been examined for non-Western samples. Therefore, the first purpose of this study was to examine the revised SIP model using Japanese youth samples.

The second purpose was to examine the differences between aggressive and non-aggressive Japanese young people in the levels of affective variables included in the model. For the examination, we developed a hypothesis that the aggressive group would display higher levels of anger and lower levels of emotion regulation than the non-aggressive group.

\subsection{An Overview of the Present Research and Hypotheses}

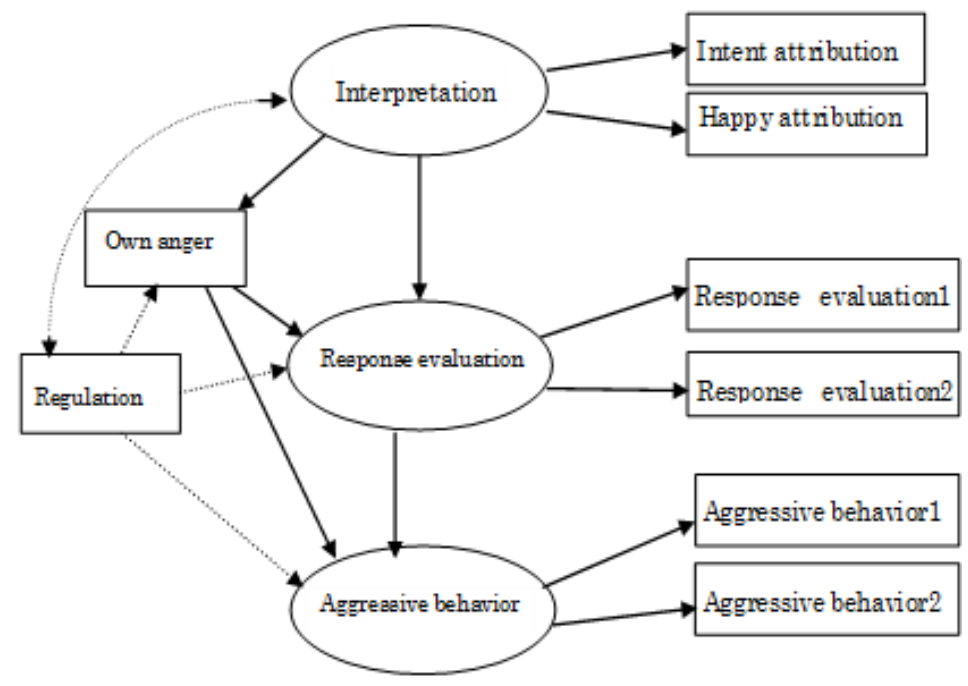

(Solid lines show facilitative paths, broken lines show suppressive paths)

Figure 1. Structural equation model of emotion processes in SIP.

The present research was designed based on the revised SIP model (Figure 1). Although the original model consists of numbers of cognitive and affective variables, we focused on three cognitive variables, interpretation, response evaluation and the decision of aggressive enactment, and two affective variables, anger and emotion regulation. This model posits 
that the perception of the other party's hostile intent enhances the positive evaluation of aggressive behavior, which in turn, facilitates the decision of enactment of aggressive behavior; hostile biases induce anger, which also induces the positive evaluation of and the decision of enactment of aggressive behavior; and emotion regulation suppresses the attribution of hostile intent, positive evaluation of aggressive behavior and anger, leading to a low level of aggression enactment. We measured the tendency toward socially desirable responses to controlling aggression in the analysis.

The hypotheses of this research were the following: the revised SIP model in which affective variables (anger and emotion regulation) are incorporated will explain the decision of aggressive behavior to a greater extent than the original SIP model (Hypothesis 1); aggressive participants will display more anger and display less emotion regulation than non-aggressive participants (Hypothesis 2); and aggressive participants will perceive the other party's intent as more hostile and evaluate aggressive behavior more positively than non-aggressive participants (Hypothesis 3 ).

In order to examine these hypotheses, we conducted two role-playing studies using different samples of Japanese youth: in Study 1, a well-adjusted sample consisting of Japanese college and vocational school students and in Study 2, an ill-adjusted one consisting of Japanese juvenile delinquents who were committed to a juvenile classification home. These samples differed in ages and the circumstances of the study: the former sample participated in the study in their schools, but the latter sample did it during being incarcerated for the juvenile trial. Main focus was on comparisons between groups of high aggression and of low aggression in each sample, but the criterion of group differentiation was different between the studies. Thus, we conducted the analyses separately for these samples.

\section{Study 1}

\subsection{Participants}

One hundred and thirty Japanese male college and vocational school students $(M$ age $=19.77 \pm 1.24)$ participated in the study.

\subsection{Procedure}

Participants joined this study in classrooms. They were asked to read three scenarios depicting situations provoking reactive aggression that were used in Aizawa's previous study [25]. Participants were requested to rate their own anger, the other party's hostile intent and happy emotions, and the extent to which they would use emotion regulation (distraction, suppression, and reappraisal) and aggression on a 9-point rating scale ranging from 1, "Not at all," to 9, "Definitely." The participants also filled out the Japanese version of the Balanced Inventory of Desirable Responding [26, 27] and the Proactive-Reactive Aggressiveness scales [28, 29]. ${ }^{1}$

1 In Studies 1 and 2, the human rights of participants were considered. The following statements were printed clearly on the top sheet of the questionnaire:

\subsection{Measures}

\subsubsection{Social Information Processing Variables}

The scenarios depicted three interpersonal conflict situations ("A person bumped your shoulder when you were walking down the road, and the person walked away without saying anything," "A person turned off the lights when you were reading a book in a classroom," and "A taxi drove by, ignoring your intention to hail it.") based on Aizawa' [25]. In the analysis we used total scores of each variable across three scenarios since Aizawa reported substantial correlations in each variable between the scenarios.

Participants were instructed to imagine that they were actually experiencing these episodes. After reading each scenario, participants were requested to rate the following cognitive and affective variables.

Attribution of hostile intent to the provoking person was assessed to ask participants to rate the extent to which they perceived that the person intentionally bumped into them (turned off the lights or ignored their intention to hail the cab) to on a 9-point rating scale ranging from 1, "Not at all," to 9, "Definitely." Perception of pleasure of the provoking person was assessed to ask participants to rate how strongly they perceived that the provoking person felt pleasure.

Own anger was assessed to ask participants to rate how strongly they would feel anger if they were the victim. The decision of aggressive behaviors was assessed to ask participants to rate the extent to which they would decide to perform two aggressive behaviors (aggression 1: "chasing the person to make him apologize" and aggression 2: "catch the person's shoulder to turn him around") on a scale ranging from 1 "Not decide at all" to 7 "Definitely decide." Evaluation of aggressive behavior was assessed to ask participants to rate the extent to which they thought each of the aggressive behaviors was good on a scale ranging from 1 "Not good at all" to 7 "Definitely good".

By modifying items used in [22], we constructed items to measure three adaptive modes of emotion regulation (distraction, suppression, and reappraisal). Participants were asked to indicate the extent to which they would take the following actions to make them feel better: distraction ("talk about it with someone" and "do something fun"), suppression ("avoid thinking about it" and "forget it"), reappraisal ("it was an accident" and "I had bad luck").

\subsubsection{Social Desirability}

The 24 items of the Japanese version of the Balanced Inventory of Desirable Responding (BIDR) [26, 27] were used to measure socially desirable response tendencies. The BIDR incorporates self-deceptive enhancement (honest but overtly positive responding) and impression management (bias toward pleasing others). Participants were requested to respond to all items on a 7 -point rating scale ranging from 1 ,

"There is no right or wrong answer." "If you do not want to answer some questions, please skip these." "Because survey answers are analyzed statistically, personal answers are not identified." The Human Research Committee of Shokei Gakuin University (registration number: 016-006) approved the study. 
"Not true at all," to 7, "Definitely true."

\subsubsection{Trait Aggression}

Proactive-Reactive Aggressiveness scales [28, 29] were used to measure participants' trait aggression. (Proactive aggression: "I get what I want by might.", "It's easy to scare peers into submission.", Reactive aggression: "I get mad easily.", " If someone disturbs me, I can't help giving tit for tat.", Participants were asked to rate the 30 -item proactive aggression scale from 1, "Not uncharacteristic of me at all" to 7, "Definitely characteristic of me," and 12-item reactive aggression scale from 1, "No," to 4, "Yes."

\subsection{Results}

\subsubsection{Correlations Among the Variables}

Descriptive statistics of the SIP and emotion variables are presented in Table 1. Because the reactive aggression and proactive aggression scales were significantly positively correlated with one another $(r=.64, p<.01)$, they were combined into a single scale of trait aggression. The scores of each variable were averaged over three scenarios. Cronbach's alpha for trait aggression, self-deception, and impressive management were $.89, .70$, and .65 , respectively.
Table 1. Descriptive statistics of SIP and emotion in students $(N=130)$

\begin{tabular}{lll}
\hline & Mean & SD \\
\hline Self-deception & 13.78 & 3.13 \\
Impression-management & 13.22 & 3.19 \\
Hostile intent attribution & 5.26 & 1.62 \\
Happiness attribution & 2.97 & 1.51 \\
Own anger & 7.16 & 1.58 \\
Emotion regulation & 5.53 & 1.21 \\
Response evaluation 1 & 4,71 & 2.00 \\
Response evaluation 2 & 3.52 & 1.86 \\
Aggressive behavior 1 & 3.75 & 1.95 \\
Aggressive behavior 2 & 2.43 & 1.48 \\
\hline
\end{tabular}

\subsubsection{Structural Equation Analysis of the Model}

A structural equation analysis based on maximum likelihood estimation (AMOS Ver.20.0 for Windows, IBM) was applied to the hypothetical model in Figure 1. To control social desirability, we added to this model effects of impression management and self-deception and of age. Then, by deleting several insignificant passes of age and the perceived pleasure of the provoking person from this initial model, we reached the final model depicted in Figure 2. The overall fitness of the final model was at an acceptable level, as indicated by $\operatorname{chi} 2(21)=15.69, \mathrm{p}=.79, \mathrm{GFI}=.97, \mathrm{AGFI}=.95$, $\mathrm{CFI}=1.00, \mathrm{RMSEA}=.00$.

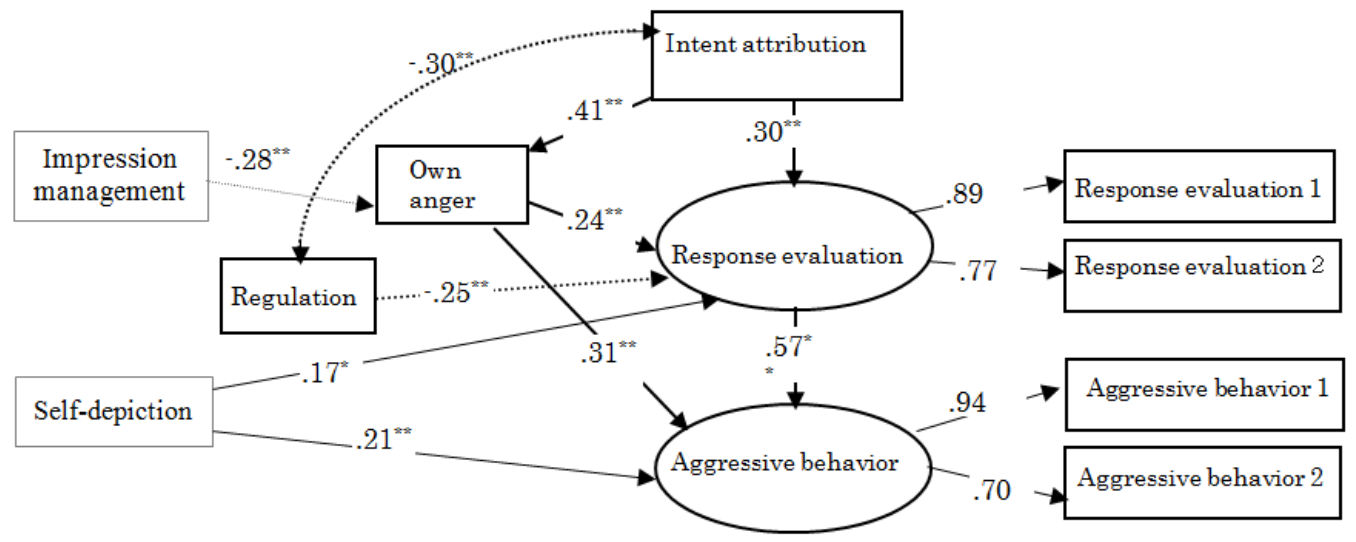

Figure 2. Structural equation model of emotion processes in SIP of college students.

$\chi^{2}=15.10 \mathrm{df}=21 p=.82$

$\mathrm{GFI}=.98$ AGFI $=.95$ RMSEA $=.00$

$\dagger \mathrm{p}<.10 * \mathrm{p}<.05^{* *} \mathrm{p}<.01$

(Solid lines show facilitative paths, broken lines show suppressive paths)

Among the social desirability variables, impression management decreased one's own anger whereas self-deception increased the positive evaluation of aggressive behavior and the decision of aggressive behavior. The attribution of hostile intent of the other party indirectly increased the decision of aggressive behavior by way of the positive evaluation of aggressive behavior and one's own anger. The attribution of hostile intent of the other party and emotion regulation were negatively correlated. Emotion regulation indirectly decreased the decision of aggressive behavior by decreasing the positive evaluation of aggressive behavior.

Regression Analyses. To examine Hypothesis 1, a hierarchical regression analysis was conducted in which the decision of aggressive behavior was a dependent variable, and other variables were independent variables. In this analysis, we combined response evaluations 1 and 2 and aggressions 1 and 2. In Step 1, only cognitive variables were entered, and in Step 2, emotion variables were added. The set of cognitive variables (the original SIP model) accounted for a significant amount of variance in the decision of aggressive behavior $\left(R^{2}\right.$ $=.46, F(5,124)=23.09, p<.01)$, and the set of emotion variables significantly increased the accounted variance of the decision of aggressive behavior $\left(\Delta R^{2}=.03, \Delta F(2,122)=4.33\right.$, $p<.05)$. The increase was because of anger $(\beta=.20)$.

\subsubsection{Differences Between Aggressive and Non-aggressive Groups}

Participants were divided into aggressive $(n=64)$ and 
non-aggressive groups $(n=66)$ by the median of the trait aggression scale (4.72). Comparing cognitive and emotional variables between these groups, we observed that aggressive participants became angrier, evaluated aggressive behavior more positively and decided more aggressive behaviors than non-aggressive participants. In addition, we observed that aggressive participants were lower in impression management and emotion regulation than non-aggressive participants. Aggressive participants perceived the other party's intent to be more hostile than did non-aggressive participants although their perceptions did not exceed the criteria (Table 2).

Table 2. Comparison between high and low aggressive group of students.

\begin{tabular}{llll}
\hline & $\boldsymbol{t}$-value & $\boldsymbol{d} \boldsymbol{f}$ & $\boldsymbol{p}$-value \\
\hline Self-deception & -.90 & 128 & .368 \\
Impression-management & 4.50 & 128 & $.000^{* *}$ \\
Hostile intent attribution & -1.78 & 128 & $.077^{\dagger}$ \\
Happiness attribution & -.27 & 128 & .790 \\
Own anger & -4.32 & 111.59 & $.000^{* *}$ \\
Emotion regulation & 4.19 & 128 & $.000^{* *}$ \\
Response evaluation & -2.85 & 128 & $.005^{* *}$ \\
Aggressive behavior & -4.62 & 128 & $.000^{* *}$ \\
\hline
\end{tabular}

${ }^{* *} P<0.01,{ }^{*} P<0.05,{ }^{\dagger} P<0.1$

Self-deception was positively associated and impression management was negatively associated with the decision of aggressive behavior $1 \quad(r=.20, p<.05 ; r=-.19, p<.05)$. These results indicated that the participants who unconsciously made themselves look good tended to decide to behave aggressively; however, those who consciously made themselves look good did not tend to decide aggressive behavior.

\subsection{Discussion}

Hypothesis 1 was supported; that is, the revised SIP model was better at predicting the decision of aggressive behavior than the original SIP model. In a study of Dutch 7-13 years old aggressive and non-aggressive children, the study [22] proposed the revised SIP model in which emotional variables were incorporated. The present study evidenced that this model is valid even for a Japanese youth, an Asian sample.

The present results replicated the findings of de Castro et al. [22] that attribution of hostile intent enhanced the decision of aggressive behavior and that emotion regulation inhibited it. The present study also concluded that response evaluation affected the processes; that is, both the effects of attribution of hostile intent and of emotion regulation on the decision of aggressive behavior were mediated by response evaluation. Considering that participants in the present study were students in Japanese schools and were assumed to be low in aggression compared with clinically aggressive children who were participants in de Castro et al. [22] recruited from behavior disorders departments of clinics for child psychiatry and special education for children with behavior problems in the Netherland, the present results imply some universality in the psychological processes in which cognitive and emotional variables shape a decision to be aggressive.

Upon further examination of the emotional variables comprising the revised SIP model, the present study revealed that aggressive participants registered higher levels of anger but lower levels of emotion regulation than the non-aggressive participants. Regarding the cognitive variables, aggressive participants more positively evaluated aggressive behavior than non-aggressive participants did; however, attribution of hostile intent did not differ between the groups, unlike the results of de Castro et al. [22].

Though aggressive participants registered relatively lower levels of emotion regulation than the non-aggressive participants, both groups showed generally high level of emotion regulation ( $\mathrm{M}$ of aggressive participants was 5.95 and that of non-aggressive participants was 5.11 on a 1-9 scale). These results seem to indicate a Japanese cultural characteristic in emotion regulation in the decision of aggressive behavior, as we discussed in the introduction. Another interpretation is that the discrepancy might be caused by a possibility that both aggressive and non-aggressive participants of the present study were relatively low levels of aggression; thus, their hostile attributional biases were not as high.

\section{Study 2}

\subsection{Introduction}

Study 1 indicated that the revised SIP model was a better predictor of the decision of aggressive behavior than the original SIP model. However, the generalizability of these findings may be limited because the participants of Study 1 were college or vocational school students who were assumed to have low levels of aggression. In Study 2, therefore, we attempted to examine the revised SIP model in a more aggressive sample, that is, juvenile delinquents. We also attempted to examine differences between relatively more aggressive and less aggressive delinquents in the levels of cognitive and affective variables included in the model in the same directions as in Study 1. In Study 2, we also measured a tendency for socially desirable responses to control it in the analysis.

The hypotheses of Study 2 were the following: the revised SIP model in which affective variables (anger and emotion regulation) are incorporated will explain the decision of aggressive behavior to a greater extent than the original SIP model (Hypothesis 1); highly aggressive delinquents will become angrier and score lower in emotion regulation than less aggressive participants (Hypothesis 2); and highly aggressive delinquents will perceive the other party's intent to be more hostile and evaluate aggressive behavior more positively than less aggressive participants (Hypothesis 3).

\subsection{Method}

\subsubsection{Participant}

Eighty-two Japanese male juvenile delinquents ( $M$ age $=16.44 \pm 1.40$ ) who were admitted to a juvenile classification home participated in the study. Their average length of incarceration is three through four weeks. Their 
criminal offenses involved both violent and non-violent ones. They were junior high or high school students, employees, or the unemployed.

\subsubsection{Procedure}

As in Study 1, participants were asked to read three scenarios and to rate the cognitive and emotional variables composing the revised SIP model. Participants were also administered the Japanese version of the Balanced Inventory of Desirable Responding [26, 27] and the Proactive-Reactive Aggressiveness scales [28, 29]. Participants were requested to respond individually to the questionnaire in their own rooms.

\subsection{Results}

\subsubsection{Correlations Among the Variables}

Descriptive statistics of the SIP model and emotion variables are presented in Table 3 . Because the reactive and proactive aggression scales significantly correlated with one another $(r=.61, \mathrm{p}<.01)$, they were combined into a single scale of trait aggression. The scores of each variable were averaged over three scenarios. Cronbach's alpha for trait aggression, self-deception, and impressive management were .92, .61, and .79 , respectively.
Table 3. Descriptive statistics of SIP and emotion in juvenile delinquents $(N=82)$.

\begin{tabular}{lll}
\hline & Mean & SD \\
\hline Self-deception & 39.83 & 8.02 \\
Impression-management & 40.98 & 12.04 \\
Hostile intent attribution & 15.39 & 4.99 \\
Happiness attribution & 8.76 & 4.69 \\
Own anger & 20.61 & 5.46 \\
Emotion regulation & 90.79 & 24.14 \\
Response evaluation 1 & 13.95 & 6.21 \\
Response evaluation 2 & 10.71 & 5.32 \\
Aggressive behavior 1 & 13.15 & 6.31 \\
Aggressive behavior 2 & 9.24 & 5.89 \\
\hline
\end{tabular}

\subsubsection{Structural Equation Analysis of the Model}

A structural equation analysis based on maximum likelihood estimation (AMOS Ver .20.0 for Windows, IBM) was applied to the hypothetical model in Figure 1. To control social desirability, we added paths from ages, impression management and self-deception to all the variables of the model. By deleting insignificant paths from this initial model, we reached the final model depicted in Figure 3, in which ages and emotion regulation were dropped because no causal path from them were significant, and a correlation between impression management and self-deception were added. The overall fitness of the final model reached an acceptable level, chi2 $(22)=27.92$, $\mathrm{p}=.18, \mathrm{GFI}=.93, \mathrm{AGFI}=.85, \mathrm{CFI}=.98, \mathrm{RMSEA}=.06$.

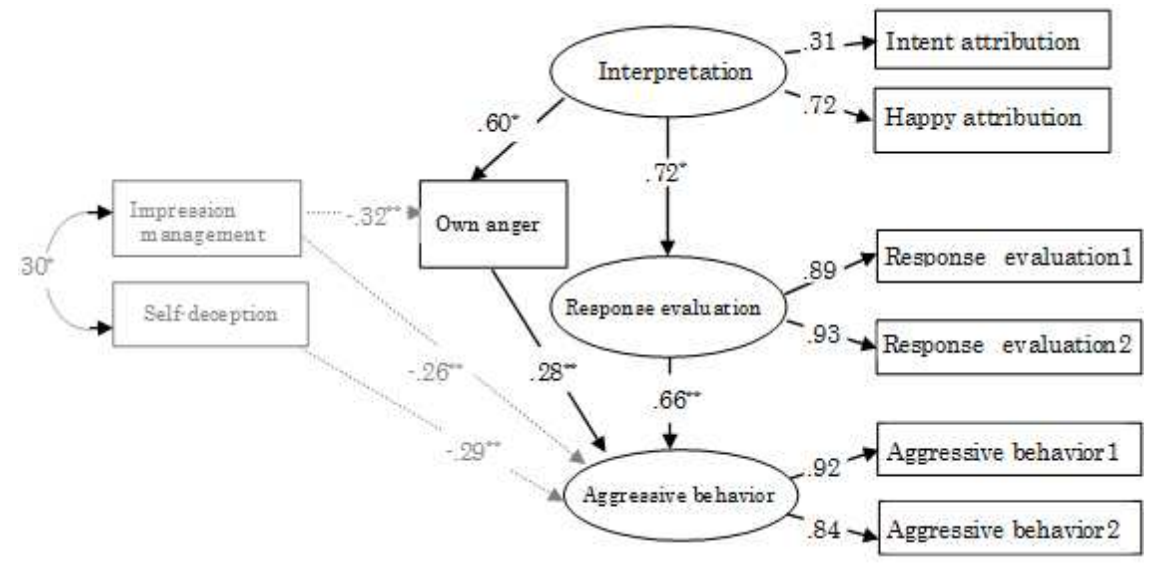

Figure 3. Structural equation model of emotion processes in SIP of juvenile delinquents.

$\chi^{2}=27.92, d f=22, p=.18$

$\mathrm{GFI}=.93$, AGFI $=.85$, RMSEA $=.06$

$\dagger \mathrm{p}<.10 * \mathrm{p}<.05^{*} p<.01$

(Solid lines show facilitative paths, broken lines show suppressive paths)

Among the social desirability variables, impression management decreased one's own anger and the decision of aggressive behavior, and self-deception decreased the decision of aggressive behavior. The attribution of hostile intent of the other party indirectly increased the decision of aggressive behavior by the positive evaluation of aggressive behavior and one's own anger. Emotion regulation did not have any significant path.

\subsubsection{Regression Analyses}

To examine Hypothesis 1, a hierarchical regression analysis was conducted in which the decision of aggressive behavior was a dependent variable and other variables were independent variables. In this analysis, we combined response evaluations 1 and 2 and aggressions 1 and 2 as in Study 1. In Step 1, only cognitive variables were entered, and in Step 2, emotion variables were added. The set of cognitive variables (the original SIP model) accounted for a significant amount of variance in the decision of aggressive behavior $\left(R^{2}=.23, F(5\right.$, $75)=27.98, \quad p<.001)$, and the set of emotion variables significantly increased the accounted variance of the decision of aggressive behavior $\left(\Delta R^{2}=.05, \Delta F(2,73)=6.00, p<.01\right)$. The increase was because of anger $(\beta=.27)$. 


\subsubsection{Differences Between Aggressive and Non-aggressive Groups}

Participants were divided into high aggressive $(n=38)$ and low aggressive groups $(n=39)$ by the median of the trait aggression scale (1.83), except for participants who had missing values. Comparing cognitive and emotional variables between these groups, we observed that high aggressive participants perceived the other party's intent to be more hostile, evaluated aggressive behavior more positively, got angrier and decided to behave aggressively more than low aggressive participants. Further, we observed that high aggressive participants were lower in emotion regulation and impression management than low aggressive participants (Table 4).

Table 4. Comparison between high and low aggressive group of juvenile delinquents.

\begin{tabular}{lllll}
\hline & $\boldsymbol{t}$-value & $\boldsymbol{d} \boldsymbol{f}$ & $\boldsymbol{p}$-value & \\
\hline Self-deception & .38 & 75 & .706 & \\
Impression-management & 4.38 & 75 & .000 & $* *$ \\
Hostile intent attribution & -2.18 & 75 & .032 & $*$ \\
Happiness attribution & -1.43 & 75 & .156 & \\
Own anger & -3.64 & 62.81 & .001 & ${ }^{* *}$ \\
Emotion regulation & 2.87 & 75 & .005 & $* *$ \\
Response evaluation & -2.72 & 75 & .008 & $* *$ \\
Aggressive behavior & -10.08 & 75 & .000 & $* *$ \\
\hline
\end{tabular}

${ }^{* *} P<0.01,{ }^{*} P<0.05,{ }^{\dagger} P<0.1$

Self-deception was not associated with other variables although impression management was negatively associated with the perception of the pleasure of the provoking person ( $r=-.25, p<.05)$, one's own anger $(r=-.45, p<.01)$, evaluation of aggressive behavior $1(r=-.22, p<.05)$, evaluation of aggressive behavior $2(r=-.29, p<.01)$, aggressive behavior 1 $(r=-.43, p<.01)$, and aggressive behavior $2(r=-.43, p<.01)$ but positively with emotion regulation $(r=.25, p<.05)$. These results indicate that the participants who consciously made themselves look good tended to perceive the provoking person's emotion as less happy, became less angry, evaluated aggressive behavior more negatively, less decided to behave aggressively and were higher in emotion regulation.

Although emotion regulation did not influence the processes of aggression, its level differed significantly between high aggressive and low aggressive participants. To examine whether the effects of emotion regulation differed between the groups, we performed a multiple regression analysis separately for each group, in which aggression was a dependent variable and other variables were independent variables. Emotion regulation was not associated with aggression in either the high or low aggressive groups. In the high aggressive group, self-deception $($ Beta $=.35, p<.01)$, one's own anger (Beta $=.30$, $p<.04)$ and response evaluation $($ Beta $=.44, p<.00)$ were unique predictors of aggression whereas in the low aggressive group, the predictors were happiness attribution $($ Beta $=.24, p<.04)$ and one's own anger $($ Beta $=.30, p<.03)$.

\subsection{Discussion}

Hypothesis 1 was supported; that is, the revised SIP model was observed to be better at predicting the decision of aggressive behavior than the original SIP model. The increase in the accounted variance of the decision of aggressive behavior was because of anger. Among the cognitive variables, however, attribution of hostile intent had the greatest effect on the decision of aggressive behavior.

Structural equation analysis of the model indicated that regulating emotion and ages were not causally associated with any other variables in the model. This finding suggests that emotion regulation does not effectively work to inhibit anger among juvenile delinquents. Unlike the student sample, the perceived pleasure of the provoking person increased the decision of aggressive behavior in juvenile delinquents, indicating that the perception of hostile intent is an instigator of aggression among juvenile delinquents.

Hypotheses 2 and 3 were also supported. As presented in Table 4, more aggressive participants became angrier, were lower in emotion regulation, perceived the other party's intent as more hostile, and evaluated aggressive behavior more positively than less aggressive participants. Unlike the student sample, more aggressive juvenile delinquents perceived the other party's intent as more hostile than less aggressive participants. This result suggests that, like the perception of pleasure in a provoking person, the biased attribution of intent leads to the decision of aggressive behavior in juvenile delinquents. Among Japanese delinquents, unlikely the student sample, the attribution of hostile intent was positively associated with aggression as often found in western samples. This also suggest that a Japanese cultural characteristic of emotion regulation is seen in the well-adjusted sample.

Findings that the level of emotion regulation differed significantly between highly aggressive and less aggressive participants and that emotion regulation was negatively associated with attribution of hostile intent in the low aggressive group and with one's own anger in the high aggressive group suggest a strong possibility that emotion regulation, perhaps indirectly, worked to reduce aggression. However, we could not obtain clear evidence for this conclusion because emotion regulation did not substantially influence aggression in both groups in regression analysis. We inferred that finding to be a reason that emotion regulation was generally weak among juvenile delinquents. We will consider this topic in the general discussion.

\section{General Discussion}

In both Studies 1 and 2, the revised SIP model was observed to be better at predicting the decision of aggressive behavior than the original SIP model. The increase in the accounted variance of the decision of aggressive behavior in the revised model was because of anger in both studies. Among cognitive variables, response evaluation (positive evaluation of aggressive behavior) accounted for the decision of aggressive behavior the most.

The perceived pleasure of the provoking person, which is a component of the interpretation step of the model, had a significant causal path to aggression only in the juvenile 
delinquents. This result suggests that juvenile delinquents tended to perceive the other person's intent as more hostile, and this biased cognition induced the decision of aggressive behavior.

Highly aggressive participants became more angrier and were lower in emotion regulation than low aggressive participants both in the student and the juvenile delinquent samples. In the juvenile delinquents, it was also observed that emotion regulation did not suppress the decision to engage in aggressive behavior and that such unalleviated anger instigated the decision of aggressive behavior. These results suggest, as previous studies have noted (de Castro et al., 2005), that highly aggressive participants, have deficits not only in the cognitive process but also in emotion regulation.

These results demonstrated that the revised SIP model has a validity for understanding aggressive responses of Japanese youths especially the critical roles of emotion regulation in their decision processes of aggressive behavior.

The original SIP model was proposed to explain the aggressive behavior of reactively aggressive children and has been examined from this perspective [3]. de Castro et al [22] attempted to construct a more comprehensive SIP model by including emotion variables of anger and emotion regulation in the original model. However, the results of our study demonstrated that in juvenile delinquents, emotion regulation did not work sufficiently to suppress the decision of aggressive behavior and that only the variable of anger should be included in the original model. This finding suggests that the original SIP model can explain the decision process of the aggressive behavior of highly aggressive people, and as Dodge noted, anger may drive the decision process as energy [30]. By contrast, the revised SIP model is an expanded model to explain the aggressive behavior of low aggressive people as well as high aggressive participants.

Emotion regulation did not work in the juvenile delinquents. There appear to be two possible interpretations. One possibility is that although juvenile delinquents can regulate their emotions adaptively, their ability to do so is not high, and they tend to feel strong anger, which they often fail to control. Juvenile delinquents may be likely to engage in aggression because the uncontrolled anger distorts social perception to produce aggressive motivations.

The other interpretation is that the research procedures adopted by the present study influenced the results. The participants of Study 2 were juvenile delinquents who were waiting for a juvenile trial. Although they were told that participation in the study had no relation to the court trial, they may have felt some social evaluation by responding to the questionnaire, distorting their responses in some cases. Thus, it is possible that the juvenile delinquents may have rated the level of their own emotion regulation higher than what it truly was. This possibility is supported by the fact that impression management has higher correlation with cognitive and emotional variables in juvenile delinquents than in school students.

Our participants were adolescent and young adults, while those of de Castro et al. [22] were 7-13 years old children. The age difference might have caused differences in the results.
SIP model of aggression postulates that young children behave aggressively by anger, but as their cognitive abilities mature and they are engaged in more complex social interactions, children gradually acquire reflective SIP skills [31]. Research has also demonstrated that aggressive behavior and the attribution of hostile intent decreases with age in social conflicting situations [32]. Therefore, our participants are assumed to be less aggressive, in general, than those of de Castro et al [22]. Nevertheless, the present results generally replicated de Castro et al. findings [22], suggesting that the revised SIP model can be applied to aggression in the youth. However, further research is necessary to explicate developmental aspects in the model.

These two studies demonstrated that emotion regulation substantially affects levels of aggression. However, the evidence is not definitive because it was obtained using hypothetical scenarios. Further investigation is necessary, therefore, in which aggressive behavior is measured in more realistic situations ${ }^{2}$.

\section{Conclusion}

The current studies demonstrated the validity of the revised SIP model of aggression, which integrated emotion, with Japanese young people. Our results showed that hostile intent, anger and positive evaluation of aggressive behavior increased aggressive behavior as de Castro et al. [22]. These also demonstrated that the revised model was significantly better in the prediction of aggression than the original model.

However, unlike previous study [22], our results showed that emotion regulation did not work in the juvenile delinquents. We referred two possible interpretations of this results. Further investigation is needed.

\section{References}

[1] Crick, N. R., \& Grotpeter, J. K. (1995). Relational aggression, gender, and social-psychological adjustment. Child development, $710-722$.

[2] Dodge, K. A. (1986). A social information processing model of social competence in children. In M. Perlmutter (Eds.), The Minnesota Symposium on Child Psychology., 18 (pp. 77-125). Hillsdale, NJ: Lawrence Erlbaum Associates, Inc.

[3] Crick, N. R., \& Dodge, K. A. (1994). A review of reformulation of social information processing mechanisms in children's social adjustment. Psychological Bulletin, 115, 74-101.

[4] Flavell, J. H. (1974). The development of inferences about others. In T. Mischel (Eds.), Understanding other persons. Totowa, NJ: Rowman \& Littlefield.

2 In Studies 1 and 2, the human rights of participants were considered. The following statements were printed clearly on the top sheet of the questionnaire: "There is no right or wrong answer." "If you do not want to answer some questions, please skip these." "Because survey answers are analyzed statistically, personal answers are not identified." The Human Research Committee of Shokei Gakuin University (registration number: 016-006) approved the study. 
[5] Goldfried, M. R., \& d'Zurilla, T. J. (1969). A behavioral-analytic model for assessing competence. In C. D. Spielberger (Eds.) Current topics in clinical and community psychology (vol. 1, 151-196). New York: Wiley.

[6] Newell, A., \& Simon, H. (1972). Human problem solving. Englewood Cliffs, NJ: Prentice-hall.

[7] Hayes, J. R. (1981). The complete problem solver. Philadelphia: The Franklin Institute Press.

[8] McFall, R. M. (1982). A review and reformulation of the concept of social skills. Behavioral assessment, 4 (1), 1-33.

[9] McFall, R. M., \& Dodge, K. A. (1982). Self-management and interpersonal skills learning. Self-management and behavior change: From theory to practice, 353-392.

[10] Dodge, K. A. (2010). Social information processing patterns as mediators of the interaction between genetic factors and life experiences in the development of aggressive behavior. In Phillip R. Shaver \& Mario Mikulincer (Eds.) Human aggression and violence: Causes, manifestations, and consequences. (pp. 165-186). Washington, DC: American Psychological Association.

[11] Lemerise, E. A., \& Arsenio, W. F. (2000). An integrated model of emotion processes and cognition in social information processing. Child Development, 71, 107-118.

[12] Eisenberg, N., Fabes R. A., Guthrie I. K., Murphy, B. C., Maszk, P., Holmgren, R., et al. (1996). The relations of regulation and emotionality to problem behavior in elementary school shildren. Development and Psychopathology, 8, 141-162.

[13] Hubbard, J. A., Smithmyer, C. M., Ramsden, S. R., Parker, E. H., Flanagan, K. D., Dearing, K. F., Relyea, N., \& Simons, R. F. (2002). Observational, Physiological, and Self-Report Measures of Children's Anger: Relations to Reactive versus Proactive Aggression. Child Development, 73, 1101-1118.

[14] Bettencourt, B. A., Talley, A., Benjamin, A. J., \& Valentine, J. (2006). Personality and aggressive Behavior under provoking and neutral conditions: A meta-analitic review. Psychological Bulletin, 132, 752-777.

[15] Berkowitz, L. (1993). Aggression: Its causes, consequences, and control. New York: Megraw-Hill.

[16] Nomellini, S., \& Katz, R. C. (1983). Effects of anger control training on abusive parents. Cognitive Therapy and Research, 7 , 57-67.

[17] Barbour, K. A., Eckhardt, C. I., Davison, G. C., \& Kassinove, H. (1998). The experience and expression of anger in maritally violent and maritally discordant-nonviolent men. Behavior Therapy, 29 (2), 173-191.

[18] Graham, S., Hudley, C., \& Williams, E. (1992). Attributional and emotional determinants of aggression among African-American and Latino young adolescents. Developmental Psychology, 28, 731-740.

[19] Lockhman, J. E., \& Wells, K. C. (2002). Contextual social-cognitive mediators and child outcome: A test of the theoretical model in the Coping Power program. Development and Psychopathology, 14, 945-67McFall, R. M. 1982 A review and reformulation of the concept of social skills. Behavioral Assessment, 4, 1-35.

[20] de Castro, B. O. (2010). Rage, Revenge, and Precious Pride. In Arsenio, W. F \& Lemerise, E. A. (Eds) Emotion, Aggression, and Morality in Children. (pp. 53-74). American Psychological Association, Washington, DC.

[21] Cole, P. M., Martin, S. E., \& Dennis, T. A. (2004) Emotion regulation as a scientific construct: Methodological challenges and directions for child development research. Child Development, 75, 317-333.

[22] de Castro, B. O., Merk, W., Koops, W., Veerman, J. W., \& Bosch, J. D. (2005). Emotions in social information processing and their relations with reactive and proactive aggression in referred aggressive boys. Journal of Clinical Child and Adolescent Psychology, 34 (1), 105-116.

[23] Adam, H., Shirako, A., \& Maddux, W. W. (2010). Cultural variance in the interpersonal effects of anger in negotiations. Psychological Science, 21 (6), 882-889.

[24] Kornadt, H. J., Hayashi, T., Tachibana, Y., Trommsdorff, G., \& Yamauchi, H. (1992). Aggressiveness and its developmental conditions in five cultures. In S. Iwasaki, Y. Kashima \& L. Kwok (Eds.) Innnovation in Cross-cultural Psychology. (pp. 220-268), Amsterdam: Swets \& Zeitlinger.

[25] Aizawa, N. (2011) Attribution of hostile intent, avoiding intent interpretations, and emotional reaction in interpersonal conflict situations: a hypothetical-situation questionnaire and its validity. Journal of Japanse Clinical Psychology, 29, 365-370.

[26] Paulhus, D. L., (1991). Measurement and control of response bias. In J. P., Robinson, P. R. Shaver, \& L. S. Wrightsman (Eds.), Measure of personality and social psychological attitudes. (pp. 17-59), New York: Academic Press.

[27] Tani, I. (2008) [Development of Japanese Version of Balanced Inventory of Desirable Responding (BIDR-J). The Japanese Journal of Personality, 17, 18-28.

[28] Hamaguchi, Y. (2004). The Creation of Reactive Aggression Scale-for Junior High School Students-The Revised Reactive and Instrumental Aggression Scales (RIS for Jounior High School Students)], Paper session presented at the meeting of The Japanese Association of Educational Psychology, Toyama.

[29] Hamabuchi, Y. (2005). [Study on construction of the self-report type proactive aggression scales for junior high school students. The Japanese Journal of Counseling Scienc, 38, 183-194.

[30] Dodge, K. A. (1991). The structure and function of reactive and proactive aggression. In D. Pepler \& K. H. Rubin (Eds.) The development and treatment of childhood aggression. (pp. 201-218). Hillsdale, NJ: Lawrence Erlbaum Associates, Inc.

[31] de Castro, B. O. (2004). The development of social information processing and aggressive behaviour: Current issues. European Journal of Developmental Psychology, 1 (1), 87-102.

[32] Toda, M. \& Watanabe, K. (2012). Social Information Processing and Development of Interpretative and Reactive Behavior towards Ambiguous Attacks. The Japanese Journal of Developmental Psychology. 23 (2), 214-223. 